\title{
Casa Abrigo: A Solução ou o Problema? ${ }^{1}$
}

\author{
Maria José Coutinho² \\ Universidade de Trás-os-Montes e Alto Douro - UTAD \\ Ana Isabel Sani \\ Faculdade de Ciências Humanas e Sociais - UFP
}

\begin{abstract}
RESUMO - Este artigo apresenta um estudo qualitativo que analisou o ajustamento psicológico de nove crianças em Casas Abrigo à luz dos significados atribuídos à experiência acolhimento. Da análise de conteúdo com recurso ao programa informático NUD*IST emergiram cinco constructos chave associados à experiência acolhimento: integração/superação, suporte, responsabilização, disciplina e segurança. Os resultados reforçam a posição de que o ajustamento psicológico das crianças é complexo e fortemente determinado pelas significações construídas. O acolhimento possibilita a minimização da sintomatologia desadaptativa.
\end{abstract}

Palavras-chave: criança, violência interparental, representações, casas abrigo.

\section{Shelter home: A Solution or a Problem?}

\begin{abstract}
This article presents a qualitative study that analyses the psychological adjustment of nine children in a shelter home in the light of the meaning attributed to the sheltering experience. From the analysis done with the software NUD*IST five key constructs related to the sheltering experience emerged: integration/overcoming, support, responsibility, discipline and security. The results strengthen the belief that the psychological adjustment of children is complex and highly determined by constructed meanings. The shelter homes offer the possibility to minimize the negative effects in children.
\end{abstract}

Keywords: children, interparental violence, representations, shelters

As casas abrigo constituem um equipamento fundamental na resposta às mulheres e crianças vítimas de violência, nomeadamente as que, perante a situação de maus tratos, se vêem obrigadas a abandonar a casa de morada de família, na maioria dos casos sem recursos de qualquer natureza. Assim, as casas abrigo constituem um contexto essencial na promoção da segurança, assim como de competências e recursos necessários à reorganização do novo projecto de vida.

O aparecimento das casas de abrigo em Portugal remonta à década de 1990, o que corresponde a um atraso de cerca de duas décadas comparativamente com a realidade europeia (Baptista, Silva \& Nunes, 2004). Este surgimento tardio esteve estreitamente relacionado com as políticas legais e institucionais de combate à problemática da violência doméstica, que conheceram um forte impulso com a aprovação da Lei 61/91. Desde então, o quadro legal português tem vindo a evoluir e a aproximar-se cada vez mais da legislação internacional no que diz respeito à protecção das mulheres $\mathrm{e}$ crianças vítimas de violência familiar.

Após a fase inicial de desenvolvimento da rede pública de casas abrigo, que se traduziu, por um lado, no aumento significativo do número de equipamentos disponíveis (estima-se que existam cerca de 34 casas abrigo em Portugal), e por outro, num esforço de regulamentação das regras de funcionamento e fiscalização, assiste-se atualmente ao

1 O presente estudo foi realizado no âmbito da tese de dissertação do Mestrado em Psicologia Clínica da Universidade de Trás-os - Montes e Alto Douro (UTAD).

2 Endereço para Correspondência: APAV - Vila Real, Edifício do Governo Civil, Largo Conde de Amarante, 5000-529 Vila Real, Portugal. Telefone/fax - 259375521 debate público sobre as práticas e necessidades de intervenção nestes settings. De um tipo de ajuda patriarcal, tem-se evoluído progressivamente para uma forma de intervenção mais profissional (Baptista \& cols., 2004). Neste contexto, tem havido uma crescente tomada de consciência dos desafios que os menores que se encontram em acolhimento juntamente com as suas mães, colocam às equipes técnicas. Inicialmente o trabalho desenvolvido nas casas abrigo destinava-se sobretudo ao apoio directo às mulheres, sendo que o apoio às crianças era considerado por arrasto, nunca tido como uma responsabilidade direta. Cada vez mais as casas abrigo preconizam no projeto global de intervenção com cada agregado familiar, planejado pelas equipes técnicas, um acompanhamento sócio-educativo das crianças, tendo em conta as necessidades individuais das mesmas. Deste modo, procuram assegurar uma intervenção individualizada da criança, em clima de segurança afetiva e física, com vista a contribuir para a sua estabilidade e desenvolvimento global.

No entanto, e não obstante os progressos verificados, resulta claro que existe um insuficiente conhecimento e reflexão sobre o impacto da experiência do acolhimento na vivência subjetiva das crianças e sobre as necessidades de intervenção com as mesmas. É escassa ou praticamente inexistente a investigação em Portugal com crianças expostas à violência interparental e acolhidas em casa abrigo. A investigação na área da vitimação infantil tem consistido preferencialmente em estudos quantitativos que analisam os efeitos adversos do testemunho da violência no ajustamento psicológico das crianças. Existe pouco conhecimento empírico que foca a significação da violência interparental pelas crianças e o impacto do acolhimento no ajustamento psicológico das 
mesmas, constituindo os trabalhos de Rodrigues (2006), Coutinho (2008) e Sani (2002, 2003, 2004) uma exceção a este nível, na medida em que encerram uma metodologia qualitativa na análise das representações das crianças da violência familiar. Priorizamos assim a necessidade de promover a produção de conhecimento focalizado nas crianças tendo sempre, como objetivo último, a melhoria na qualidade dos serviços prestados.

A experiência do acolhimento em casa abrigo constitui para as crianças que estiveram expostas à violência interparental um desafio, uma influência única e que segundo Fantuzzo, Mohr e Noone (2000) pode contribuir significativamente para o aumento do nível de estresse psicológico. Desta forma julgamos importante perceber como as crianças acolhidas em casas abrigo constroem as suas representações do acolhimento e de que forma estas influenciam o seu funcionamento psicológico. A questão central deste estudo reside, portanto, na compreensão dos significados construídos por um grupo de crianças sobre todo o processo inerente ao acolhimento (causas, processo e consequências).

$\mathrm{O}$ conhecimento dos processos representacionais das crianças, como mediadores do impacto, pressupôs a opção por uma metodologia de natureza qualitativa. Procuramos, por meio de procedimentos de cariz indutivo, responder à seguinte questão: $\mathrm{O}$ ingresso numa casa abrigo perspectiva-se, do ponto de vista da criança, como a melhor solução?

As metodologias qualitativas postulam a primazia da experiência subjetiva enquanto fonte de conhecimento, o estudo dos fenômenos a partir da perspectiva do sujeito e dos seus marcos de referência (Ericksen \& Hendersen, 1992) e visam a construção de uma hipótese teórica e explicativa, a partir dos próprios dados e não de teorias previamente construídas. Ao optar por esta metodologia estaremos capazes de fazer descobertas sobre a forma como as crianças percebem as suas experiências e perceber o impacto que essas perspectivas têm na experiência e comportamento individuais, nomeadamente na modelagem dos comportamentos, pensamentos e sentimentos (Ericksen \& Hendersen, 1992; Sani, 2002). O estudo segue as linhas de orientação dos estudos fenomenológicos, que, segundo Patton (conforme citado por Peled, 1998) focam-se na questão: qual é a estrutura e a essência da experiência deste fenómeno para estas pessoas? Os investigadores tentam descrever a experiência subjetiva dos sujeitos da maneira mais completa possível, explorando o fenômeno sem expectativas preconcebidas.

$\mathrm{O}$ interesse empírico por este tema, além do propósito de natureza conceptual, teve subjacente um compromisso de natureza prática, já que uma das preocupações foi tirar ilações em termos de necessidades e formas de intervenção. Compreender como as crianças são afetadas, como dão significado e como lidam com as suas experiências permite-nos intervir de forma a minimizar o dano e maximizar respostas de coping adequadas. O estudo nesta população específica, ajuda-nos a clarificar algumas inquietações resultantes do trabalho terapêutico com as crianças acolhidas em casas abrigo, que como resposta especializada, se apresenta ainda como um lugar por desvendar.

\section{Método}

\section{Participantes}

A constituição da amostra para o presente estudo obedeceu ao critério de amostragem teórica, na medida em que na escolha pela diversidade (etária, género, experiência, etc.) está subjacente a necessidade de se garantir a representatividade experiencial, que só esta poderá determinar o fecho da amostra. Assim, a amostra compôs-se por 9 crianças, de ambos os géneros, com idades entre os 6 e os 15 anos, acolhidas há mais de dois meses em casas abrigo da Associação Portuguesa de Apoio à Vítima (Casa Abrigo Sophia e Alcipe), e da Santa Casa de Misericórdia do Porto (Casa Abrigo de Santo António). A experiência de exposição à violência no seu contexto doméstico teve uma duração entre os 3 e os 14 anos. Em cinco casos esse tempo é correspondente à idade da criança entrevistada, o que revela que a exposição à violência se verifica desde o nascimento. Estas crianças permaneceram nas casas abrigo entre os dois e os nove meses e em sete dos nove casos, o ingresso na casa abrigo constituiu a primeira saída da criança e da mãe de casa. Quanto ao ofensor, este era na maioria dos casos o pai biológico das crianças, sendo que só em dois casos a violência testemunhada era perpetrada pelo padrasto.

\section{Instrumentos}

Os dados foram recolhidos a partir de um roteiro de entrevista semi-estruturado construído com base na literatura $^{3}$. Neste roteiro são abordados três momentos temporais distintos: (a) a fase anterior ao ingresso na casa abrigo, quando viviam em violência; (b) a saída da casa de morada de família; e (c) o acolhimento em casa abrigo. Formalmente, a entrevista está estruturada em três etapas sequenciais: (a) o estabelecimento de uma relação de confiança e empatia entre o entrevistador e a criança; (b) o relato dos acontecimentos relevantes na sua dimensão comportamental, cognitiva e emocional, nos três momentos temporais distintos, evocando-se as memórias dos eventos mais antigos para os mais actuais; e (c) a finalização da entrevista, sumariando o que foi relatado e promovendo uma atmosfera positiva, procurando que a criança saia da entrevista com um auto-conceito positivo (Sani, 1999, 2002). Neste artigo, tal como previamente especificado, apenas nos iremos debruçar sobre os resultados obtidos relativamente ao período do acolhimento.

\section{Procedimento}

As entrevistas foram realizadas entre janeiro e setembro de 2007, tendo sido assegurados a confidencialidade, a privacidade e o anonimato, considerados princípios chave na

3 O guião de entrevista foi elaborado tendo como referência a "Entrevista à criança e às mães vítimas de experiência abusiva" de Sani (2003), a "Entrevista de Avaliação-Intervenção com crianças vitimizadas" de Sani (1999) e o trabalho empírico desenvolvido por Ericksen e Hendersen (1992) com crianças testemunhas de violência interparental. 
Tabela 1. Categorias emergentes da análise dos dados relativos à criança e ao acolhimento em Casa Abrigo

\begin{tabular}{lll}
\hline & Categorias & Tópicos de Análise \\
\hline & Percepção da Realidade Casas de Abrigo & Planejada vs Emergência; Risco vs Segurança; Explicação vs Desconhecimento \\
& Reacções Imediatas ao Pai & Emocional; Cognitiva e Comportamental \\
& Percepção do Impacto do Acolhimento & Psicológico vs Físico; Unidimensional vs Muiltidimensional; Criança vs Mãe \\
& Necessidades de Ajuda e Suporte & Existente vs Inexistente; Formal vs Informal \\
& Percebido & Responsivo vs Não Responsivo; Suficiente vs Insuficiente \\
& Percepção do Passado & Reacções à Violência e à Ruptura \\
& & Existência vs Inexistência; Pessimismo vs Optimismo; Esperança vs \\
\end{tabular}

intervenção com a população vítima de crime ${ }^{4}$. A duração das entrevistas foi de aproximadamente uma hora cada, sendo as mesmas gravadas e o seu conteúdo transcrito de forma cuidadosa e detalhada. Aquando da realização das entrevistas houve diferentes reações emocionais da parte das crianças (e.g. hesitação, receio, ansiedade). O dar-lhes "voz", a oportunidade de falarem de si e do como se têm sentido e lidado com todas as mudanças recentes no seu contexto familiar foi sentido, por muitas, como algo importante.

\section{Análise dos dados}

O material empírico foi sujeito a um processo de análise qualitativo com recurso ao programa informático NUD*IST (Non-NumericalUunstructed Data Indexing, Searching and Theorising - versão 4.0), constituindo-se assim, de forma indutiva, critérios temáticos de categorização. $\mathrm{O}$ processo de codificação dos dados, e respectiva construção da grelha de análise de conteúdo (Tabela 1), foi realizado numa lógica de bottom-up, ou seja, resultou das leituras sucessivas do material empírico, por meio das quais o investigador pensou os dados, "colocou-lhe questões", procurando identificar unidades de significado emergentes (categorias) e esboçando possibilidades de estruturação. Desta análise emergiram seis categorias que encerram a percepção que as crianças tinham da realidade das casas abrigo, as reações emocionais, cognitivas e comportamentais à figura paterna, a percepção do impacto do acolhimento em si e na figura materna, as necessidades de ajuda aquando do ingresso nas instituições de acolhimento e o suporte, formal e informal, percebido e recebido, a percepção do passado familiar violento e as perspectivas de futuro. A análise da experiência das crianças seguiu de perto a categorização efetuada das entrevistas.

A leitura dos resultados teve como linha orientadora principal a Grounded Theory, cujo objetivo é desenvolver

4 O processo foi iniciado com a formalização do pedido de colaboração na investigação junto das respectivas instituições, seguindo-se a assinatura pela autora do estudo do compromisso de confidencialidade. Procedeu-se de seguida ao contacto com as mães das crianças a quem foi explicado em pormenor pelo investigador os objectivos do estudo, os procedimentos que iriam ser seguidos e a apresentação do guião da entrevista de recolha da informação, bem como o formulário de consentimento informado, que foi devidamente assinado. teoria fundamentada nos dados derivados da realidade estudada. Com este estudo, mais do que quantificar realidades, pretendemos descrever e suscitar curiosidades, a partir das narrativas das crianças, que possam impulsionar outras perspectivas sobre tão vasto tema.

\section{Resultados}

As narrativas das crianças acerca da realidade das casas abrigo encerram, de forma explícita, três constructos chave - disciplina, segurança e apoio. No que diz respeito à disciplina, parece-nos claro que, para a maioria das crianças, a experiência do acolhimento é fortemente determinada pela organização quotidiana das casas abrigo. As crianças têm clara noção de que o funcionamento da instituição de acolhimento é regido por um regulamento interno, que disciplina todos os aspectos inerentes ao dia a dia na casa (tarefas domésticas, horários, refeições), e que deve de ser obrigatoriamente cumprido por adultos e crianças.

$\mathbf{C 5}$ - ...é um sitio onde temos que cumprir regras, temos normas, temos horas para jantar, para tomar o pequeno-almoço e horas de deitar, além disso podes ir para a televisão mas com condições, não nos podemos portar mal com os mais pequenos, temos de respeitar os funcionários, a hora de jantar é das $8 \mathrm{~h}$ às 8h30, a hora do pequeno-almoço é desde acordar até às $9 \mathrm{~h} e$ nos domingos é prolongado às $9 \mathrm{~h} 30$, tu deitas-te às $9 \mathrm{~h} 30$ como as outras crianças e os adultos deitam-se depois".

Encontramos variação na forma como as crianças sentem e reagem à normalização e regulamentação do seu quotidiano, com a identificação de dois cenários distintos: algumas crianças percebem as normas de funcionamento como um potencial fator de crescimento pessoal, associado a disciplina e responsabilidade, em claro contraste com o ambiente familiar caótico em que estiveram inseridas no passado recente.

$\mathbf{C 1}$ - “...e depois há aquela coisa de regras eu adoro regras, eu adoro disciplina e sinto assim vou sair daqui um rapazinho bué de assiduo, tenho de arrumar a cama, coisas que não me punham para eu fazer e eu penso que tenho uma responsabilidade e sinto-me mais eu..."; 
No entanto, para a maioria das crianças, as regras soam a novidade, são sentidas como incômodas e restritivas da sua ação, causam estranheza e são difíceis de cumprir.

C6 - "é chato... são muitas regras, não posso sair de casa, tenho um horário casa-escola, escola-casa...apetece-me sair e não posso porque tenho horas para chegar a casa...depois existem as regras todas cá em casa...não fazemos aquelas coisas que fazemos quando estamos em casa, é muito diferente, tem muitas regras".

Apesar de terem verbalizado a não aceitação das normas de funcionamento, os menores avaliam as mesmas como justas e necessárias (C8 (C4, C5, C7) - "são um bocado más mas são justas e têm de ser cumpridas”) e quando lhes é dada a possibilidade de pensar mudanças na instituição de acolhimento a maioria não faz referência a alteração das normas.

As narrativas das crianças indiciam igualmente que as casas de abrigo cumprem a sua finalidade protetora (C7 “...é bom... porque uma pessoa sente-se à vontade, sabe que não corre perigo, tem tudo aquilo que precisa, sentimo-nos bem cá dentro"). A maioria sente-se segura nas instituições de acolhimento, não receiam eventuais novas situações de vitimação, parecendo-nos que o sentimento de segurança advém por um lado da designação abrigo (C1 - "porque a gente sabendo que é abrigo a gente sente-se seguros"), do conhecimento da finalidade destes equipamentos, ou seja, acolher provisoriamente mulheres e crianças vítimas de violência (C8 (C4) - uma casa abrigo é onde as mulheres e os filhos ficam abrigados dos homens ou das mulheres, porque podem ser as mulheres que batem nos homens) e à obrigatoriedade de manter o sigilo quanto à localização da casa de abrigo. A regra da confidencialidade é compreendida e cumprida por todas as crianças, sendo que a sua existência é justificada, segundo os menores, pela necessidade imperiosa de manter a sua segurança e da mãe.

$\mathbf{C 1}$ - "eu não dizia mesmo que pudesse... eu penso assim estou aqui a viver e se me disseram para não dizer eu não digo... eu não acho que é nenhuma obrigação, é para a minha segurança... eu estou completamente ciente que isto é para a minha segurança...digo moro para ali”.

A percepção do apoio de técnicos especializados é outro aspecto que ressalta das narrativas das crianças, adquirindo maior importância em função da percepção que a criança tem dos maiores ou menores recursos de que a figura materna dispõe para enfrentar esta nova etapa da sua vida. O apoio dos técnicos desempenha, assim, uma função securizante das reações da criança ao acolhimento, minimizando o sentimento de desesperança e pessimismo quanto ao futuro.

C7 - que é uma casa onde nos podem ajudar, que é muito bom, temos tudo o que nós precisamos, podemos construir uma vida nova e é melhor tentar porque se não tentarmos".

Além dos construtos referidos anteriormente, o discurso das crianças toca ainda na questão ambiente institucional versus familiar. A este respeito, sentimos que para as crianças, especialmente aquelas que se encontram acolhidas em instituições de pequena dimensão, de cariz marcadamente familiar, o "mundo" das casas de abrigo não é uma realidade assim tão distante das "normais" casas de família (C1 - "imagina que estás na tua casa mas que tens a casa sempre cheia e se precisares de alguma coisa tens quem te ajude ... é uma casa igual às outras, com um bocadinho de disciplina...”). Os aspectos diferenciadores destas duas realidades parecem ser a finalidade das casas de abrigo, o regulamento interno de funcionamento e o viver diariamente com várias famílias, com os inconvenientes e potencialidades que isso acarreta. $\mathrm{O}$ viver diariamente no mesmo espaço com vários adultos e crianças é descrito pelos menores ora como uma verdadeira guerra, em que é difícil conciliar diferentes modos de estar, pensar e sentir, ora como um contexto privilegiado e facilitador de aprendizagem de aptidões sociais e desenvolvimento de novos contatos sociais.

C1 - “...é esquisito... porque as outras famílias têm outros hábitos, outras maneiras de viver, outras maneiras de conviver, outros horários, outras maneiras de cozinhar";

$\mathbf{C 4}$ - ...é mau por causa das guerras... as vezes acontecem guerras e as vezes as pessoas não ajudam, não limpam...".

Nas casas de abrigo, a existência de um número elevado de crianças permite quebrar com o isolamento em que alguns menores se encontravam quando "viviam" com a violência, com a vantagem da semelhança das experiências vividas poder constituir um fator de aproximação (C9 - “...é divertido porque temos mais pessoas na família, temos as meninos para brincar").

\section{Reações Imediatas ao Pai/ Padrasto}

A integração na casa abrigo originou, por um lado, o fim da exposição continuada da criança à violência interparental, o que para a maioria é percepcionado como um acontecimento positivo, e por outro, determinou o afastamento da figura paterna. Das nove crianças, sete não tiveram qualquer tipo de contato, presencial ou telefônico, com o pai/padrasto, desde que ingressaram na instituição de acolhimento. As exceções reportam-se a duas situações em que as crianças visitaram pontualmente a figura paterna, no entanto, o aproveitamento por parte do agressor do regime de visitas estabelecido para continuar a exercer violência e controle sobre a mãe determinou o fim dos encontros.

C5 - "eu ia lá aos sábados ter com ele ate que ele ameaçou a minha mãe e deixei de ir, a minha mãe ia lá e eu ia ter com ele, eu tenho o numero dele mas só que eu não quero ligar por causa das ameaças que ele faz, ele agora já não faz mas é melhor deixar passar um tempo porque ele ainda pode começar...mas eu gostava de estar com ele só que de uma forma segura, isto é que não acontecesse nada à minha mãe... que não acontecesse ameaças que é para não prejudicar a minha mãe".

A ruptura da relação pai - criança não é sentida como uma contrariedade pelos menores, antes como uma medida de segurança, e um possível cenário de proximidade é perspectivado como assustador (C4 - “ ...credo ... fico assustada ... eu as vezes penso que o vejo ...vejo pessoas parecidas com ele... 
não dizia nada fugia”). Este afastamento parece ter agravado as reações das crianças à figura paterna. Os pais/padrastos são relembrados num discurso marcado pela ambivalência, com as crianças a expressar um padrão recorrente de emoções conflituosas, que incluem algum afeto e preocupação mas principalmente ressentimento, tristeza, dor, desilusão, raiva e confusão.

C7 - “...às vezes penso como é que ele se sente, se está bem, se não está"

C3 - “...sinto coisas más ...não sinto saudades nem falta dele... nem o quero ver nunca mais”,

C8 - "eu nunca o vou perdoar por aquilo tudo que ele fez à minha mãe".

As crianças são apanhadas entre o sentimento de que a violência está errada e que os comportamentos abusivos do pai/padrasto não são toleráveis nem justificáveis, desencadeando, em alguns casos, um claro desejo de vingança e reparação do passado $(\mathbf{C 1}$ - "eu penso nele é no que lhe podia fazer... eu só sinto é que se o apanho bato-lhe"). Algumas crianças verbalizam sonhos e pensamentos recorrentes em torno de encontros com o agressor em que a criança sai vitoriosa, outras referenciam a prisão efetiva do pai por tudo o que fez no passado (C1 - “... as vezes penso e sonho muitas vezes que ele aparece e que eu o derroto... e já acordo bem, acordo feliz”; C4 - “... agora sinto que ele que devia estar preso porque ele não podia fazer o que fez à minha mãe”). As descrições da figura paterna feitas pelas crianças baseiam-se principalmente em características psicológicas que fazem alusão a uma personalidade problemática e doente, próxima do papel de vilão.

C1 - "ele para as pessoas e simpático, agradável, faz com que as pessoas se sintam bem ao pé dele, é educado mas tem aquela, eu acho que ele tem mesmo aquela deficiência... eu as vezes até pensava que ele tem dupla personalidade... porque de um minuto para o outro ele mudava);

C9 - “...o pai é mau quando bate à mãe tem uma transformação na cara, porque quando está bem disposto tem a cara a rir, tem o olhar a rir e quando bate os olhos ficam com raiva, ódio, já não sorri, ficava zangada".

Os relatos das crianças adquirem outros contornos quando focamos a relação mãe - criança. A mãe constitui a principal figura de suporte das crianças e é descrita como responsiva e disponível, principalmente agora que não está sujeita ao controle e violência por parte do cônjuge/companheiro, parecendo-nos evidente que as crianças crêem que a relação mãe - filho(a) beneficiou com a ruptura familiar, pelo fim da turbulência causada pela violência e pela maior liberdade para a mãe poder decidir as questões referentes à educação dos filhos.

C8 - “...é fixe porque o ambiente é mais calmo e já não temos tanto movimento, porque o pai estava sempre a falar alto, a chamar pela mãe e a mãe tenta os impossiveis por nos dar coisas, nos levar a passear".

\section{Percepção do Impacto do Acolhimento}

Das nove crianças que integram a amostra, sete verbalizaram mudanças positivas em vários domínios do seu funcionamento. As mudanças identificadas abrangem o domínio comportamental, social, emocional, cognitivo e físico.

C1 - "Sinto-me assim cheio de força, alimento-me muito bem, então tenho muita energia, apetece-me sair, apetece-me correr, jogar à bola, andar de bicicleta, apetece-me fazer montes de coisas e depois comecei a sair e a fazer amigos e sinto-me cheio de energia e cheio de força para viver ... comecei a estudar outra vez, comecei a aprender, ter mais capacidade de raciocinio, a ter uma nova motivação que eu já não tinha, e comecei a ter motivação outra vez, a ter sonhos outra vez, comecei a ter desejos de fazer alguma coisa, comecei a sentir-me vivo... na escola também mudou, comecei a ser o centro das atenções, eu falo muito, faço os outros rir, convivo e comecei a sentir que as pessoas gostam de mim";

C8 - "sinto-me mais contente, feliz e seguro e estou melhor, estou mais calmo e mais contente".

A desorganização pessoal e o sofrimento emocional gerado pela exposição à violência parecem assim ter sido minimizados pelo acolhimento, ao que não parece ser alheia, mais uma vez, a questão do sentimento de segurança, tema recorrente no discurso das crianças.

C9- "pelo menos aqui não vai acontecer nada de mau como acontecia na minha casa".

As crianças mostraram-se igualmente sensíveis às mudanças ocorridas na figura materna, na sequência da integração na casa abrigo. As crianças percebem as mães como pessoas mais ativas e autônomas tanto na sua vida pessoal como social e mais disponíveis para responder às necessidades físicas e emocionais das crianças.

$\mathbf{C 1}$ - “...eu vejo ela sempre a rir-se, toda feliz, ela arranja-se, ela veste-se bem, ela toma as suas decisões e toma conta das suas coisas, eu acho que ela continua a ser a mesma mulher, está é mais ciente de si, parece-me mais confiante, mais dona do seu nariz, mais responsável também"

C9 (C2, C3, C4, C8) - "a mãe está mais contente e aliviada porque já não há ninguém que lhe bata e tem mais vontade de brincar connosco, antes não tinha".

\section{Necessidades de Ajuda e Suporte Percebido}

A integração numa casa abrigo parece ter suprido as principais necessidades físicas e psicológicas das crianças. A maioria refere que não necessitam de mais "nada", com exceção de três menores, que partilham o desejo de ter uma casa só para eles e para a mãe $(\mathbf{C 3}$ - “...preciso de ter uma casa só para mim e para a minha família”; C4 - “...sinto necessidade de sair daqui, ir para uma casa só minha”). As crianças em causa encontram-se em situação de acolhimento prolongado, com uma duração superior a seis meses, e estão integradas em instituições de grande dimensão. Não obs- 
tante o desejo de mudança do ambiente institucional para o ambiente familiar, as crianças manifestam algum receio em enfrentar novas transições, referindo explicitamente o desejo em permanecer na mesma área de residência do centro de acolhimento e no mesmo estabelecimento de ensino.

C6 - “...sair daqui, arranjar uma casa e não queria mudar de escola...agora que já me habituei também já não queria mudar".

Durante o período de acolhimento, as equipes técnicas constituíram a única fonte de suporte para as crianças e mães. Importa referir que as crianças não voltaram a ter contato com as pessoas de referência do seu passado (pares, professores, família) e que em alguns casos esta separação foi sentida como dolorosa e em outros encarada com normalidade, até porque a família já se encontrava isolada por imposição do agressor.

$\mathbf{C 1}$ - "não tenho nenhum contacto... não sinto falta porque também já não tinha contacto com eles há muito tempo, eles convidavam-me para as festas de anos e eu já começava a não poder ir, por isso não sinto falta, agora sinto falta de estar com estes aqui, estes agora é que são os meus amigos".

C3 - "eu lembro-me as vezes deles e gostava de falar com eles"; C4 - “...não, nunca mais falei com eles, só a minha mãe que fala para uma amiga e para um irmão dela, eu não posso mexer no telemóvel da minha mãe, se pudesse falava com uma amiga, uma vez falei quando ela fez anos, foi só para dar os parabéns... tenho saudades dos meus amigos...".

As crianças percebem os profissionais responsáveis pelo acompanhamento psicossocial como disponíveis e apoiadores e têm presente a importância do seu papel na ajuda da reorganização do novo projeto de vida da família.

C1 - "São o meu único ponto de referência, eu sei que se não posso recorrer à minha mãe eu posso recorrer à equipa técnica e depois a equipa técnica fala sempre muito bem comigo e eu sinto-me à vontade";

C2 - "as doutoras... ajudam a minha mãe a arranjar trabalho para ter dinheiro para termos uma casa";

C7 (C3, C4, C5, C8) - "as doutoras ajudam-nos muito.

\section{Percepção do Passado}

A análise das reações emocionais e cognitivas das crianças, desencadeadas pela recordação da violência familiar, vem alertar para potencial adverso que a exposição a este tipo de eventos acarreta no ajustamento dos menores que não se restringe apenas ao imediato. Mesmo após o restabelecimento da segurança física, o passado familiar violento continua a acarretar custos emocionais indesejáveis nas crianças, com estas a experienciar afeto negativo e reações de evitação.

$\mathbf{C 3}$ - “... sinto-me triste mas tento não pensar mais naquilo, não quero”;

$\mathbf{C 4}$ - “...evito pensar nisso, sinto-me triste...”;
C6 - "é para esquecer, ... não me apetece pensar, evito pensar no que aconteceu".

Não obstante a visibilidade de algumas marcas psicológicas, sentimos que o tema violência tem perdido protagonismo na vivência emocional e cognitiva das crianças. Na sua generalidade, as crianças revelam uma menor frequência e intensidade de emoções e cognições associadas ao passado e maior foco no futuro.

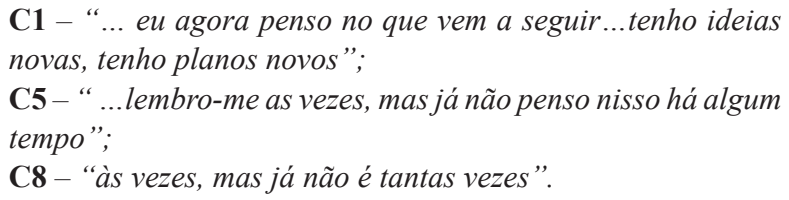

A esta evolução parece não ser alheio o fato de o sentimento de segurança ser reposto com o acolhimento. A análise revelou que a maioria das crianças acredita que não irá voltar a passar por situações semelhantes àquelas que no passado experienciaram. A possibilidade de eventos parecidos ocorrerem só se coloca caso o pai/padrasto descubra a família ou a mãe desista do processo de apoio e volte para a relação abusiva. Estas constituem razões suficientes para manter um otimismo no futuro quanto ao não voltarem a passar pelo mesmo.
C9 (C1, C2, C3, C6, C8) - “... nunca mais vai acontecer nada disso".
C7 - "se voltarmos a viver com ele sim, mas se continuarmos cá não”.

\section{Perspectivas de Futuro}

Todas as crianças foram capazes de projetar o futuro de forma otimista. O futuro após a saída da instituição de acolhimento é perspectivado por todos os menores como "melhor" do que o passado (violência) e o presente (acolhimento), o que em termos de ações concretas traduz-se na conquista de um espaço próprio para a família, aspecto considerado pelas crianças como essencial na reorganização da sua vida familiar.

C3 - "o futuro vai ser melhor porque vou ter uma casa só para mim e para a minha mãe e para as minhas irmãs".

C9 - “...vai ser boa, já não tenho o pai a bater a mãe”.

A maioria das crianças colocou "ter uma casa para mime para a minha mãe" como um dos principais desejos pessoais. Além de conseguirem traçar um plano de ação para o futuro, as crianças desejam ter paz, alegria, entre outros aspectos necessários à normalidade do sistema familiar (C7 - "um futuro bom, vamos ser muito felizes e vamos conseguir ter paz ...vou conhecer novas pessoas, novos amigos"). Não deixa de ser curioso que, apesar do fim do acolhimento, há crianças que reconhecem como aspecto positivo a existência de pessoas (técnicos) que continuarão a constituir uma fonte importante de suporte. 
C1 - “... eu penso sempre que vai ser melhor e penso que vou continuar a crescer, e começar a ter a minha vida e a começar a ter que depender mais de mim e penso que saio daqui e vou poder continuar a contar com o apoio da APAV".

O componente humano parece ser um dos aspectos inerentes ao acolhimento mais valorizados pelas crianças, pelo potencial na multiplicação de novos contatos sociais, quer pelo apoio especializado que os técnicos promovem ( $\boldsymbol{C} 9$ - "não sei, acho que sim, dos meninos").

As crianças revelaram ainda capacidade de retirar aprendizagens do passado doloroso, nomeadamente sobre os direitos das mulheres, a não aceitação da violência como forma de relacionamento e resolução de conflitos e sobre estratégias de confronto adequadas. Não obstante o impacto negativo da exposição à violência, os menores não revelaram um negativismo exagerado, nem indiciaram a aceitação e aprendizagem de padrões de conduta baseados no controle, poder e agressão.

$\mathbf{C 1}$ - " aprendi que sempre que poder vou lutar pelos direitos das mulheres... eu acho que os homens deviam ser educados desde crianças... tu obedeces porque tens de obedecer, não é preciso ser fascista... a mulher é mais importante do que tudo......";

C4 - "aprendi que não se deve bater nos outros e que devemos ser bem educados com todos e mais nada";

C6 - "aprendi que não posso ser igual ao meu pai quando for maior";

$\mathbf{C 7}$ - “ uma pessoa quando tem problemas não se deve calar mas sim falar com pessoas”.

\section{Discussão}

Da leitura atenta dos resultados emergiram cinco constructos associados à experiência acolhimento e que constituem o elemento chave na resposta às inquietações que deram o mote ao trabalho empírico desenvolvido nomeadamente, o constructo superação/integração, suporte, responsabilização, disciplina, segurança.

$\mathrm{O}$ acolhimento em casa abrigo possibilitou mudanças na forma como as crianças se percebem, aos outros e ao meio que as rodeia, no sentido de uma concepção potencializadora da auto-estima e crescimento pessoal (superação/integração). As crianças revelaram maior consciência dos seus recursos e da sua competência na gestão dos desafios que se colocam nos vários contextos e maior centração e uma projeção otimista do futuro. O passado tem cada vez menos protagonismo na vivência emocional e cognitiva das crianças, o que constituiu um forte indicador do efeito securizante e normalizador da experiência de acolhimento, e assume um caráter irremediável, por oposição ao presente que carrega consigo a possibilidade de mudança. O futuro é visto como "melhor", sendo que melhor tem subjacente a crença de que a violência era um estorvo à normalidade e a institucionalização, apesar de todos os esforços, não deixa de ser um contexto artificial e provisório. No momento da violência, o futuro não tinha simplesmente lugar, era percebido como a continuidade do presente terrível em que a única certeza era a antecipação da vitimização futura, sendo que o futuro começou a ter lugar na vida das crianças quando se vislumbrou a possibilidade de saída de casa. O pessimismo e a desesperança deram então lugar ao otimismo e esperança na resolução do problema.

As crianças são capazes de identificar na sua vida aspectos capazes de lhes promover segurança e um otimismo quanto ao futuro, entre os quais se destaca a nomeação de pessoas que identifica como reais figuras de suporte e proteção, em que os principais intervenientes são as equipes técnicas e as mães (suporte). A importância do apoio das equipes técnicas deriva da percepção da criança dos maiores ou menores recursos da figura materna para enfrentar a nova etapa. Os técnicos das instituições de acolhimento são percebidos como disponíveis, apoiadores e fundamentais no apoio à reorganização do projeto de vida das famílias. O trabalho multidisciplinar desenvolvido nas casas abrigo, com uma intervenção integrada numa lógica de empowerment, contribuiu para normalização das reações ao acolhimento e integração desejadas, quer das crianças quer das mães, dotando-as das ferramentas que lhes permitem conseguir operar mudanças nas diversas áreas das suas vidas, minimizando os efeitos decorrentes da exposição à violência continuada. Ao contrário do que acontecia no passado recente, as mães surgem como ativas, autônomas e disponíveis para responder às necessidades emocionais $\mathrm{e}$ físicas das crianças. $\mathrm{O}$ acolhimento proporcionou assim, na perspectiva das crianças, o ambiente favorável ao bem-estar, reflexão e reorganização do projeto pessoal da figura materna, contribuindo de forma decisiva para a superação do seu estado traumático, que as impossibilitava de desempenhar de forma consistente o seu papel de mães.

Relativamente à figura paterna, o acolhimento conduziu a um agravamento das reações emocionais e cognitivas das crianças para com esta figurar, determinando a adoção de estratégias de afastamento físico e emocional em relação ao progenitor. O progenitor é representado como uma figura ameaçadora e problemática, longe das funções de estabilidade e segurança habitualmente atribuídas às principais figuras cuidadoras e é identificado como o único e principal responsável pela violência e perda da família intacta (responsabilização). Para este distanciamento parece ser determinante a identificação pelas crianças de um quadro de atribuições causais explicito (identificação de causas internas estáveis e externas estáveis), como estando na base do comportamento problemático, com naturais implicações na representação da figura paterna e na crença na reincidência da violência, pelo que um possível cenário de proximidade é perspectivado como assustador, uma ameaça ao sentimento de segurança, entretanto estabelecido.

Até o conceito que poderia estar associado a uma representação mais negativa (disciplina), é perspectivado como uma mais valia. As casas abrigo são representadas em torno de conceitos como ordem, regulamentação e previsibilidade em contraste com o ambiente familiar instável, caótico, imprevisível e ameaçador. Uma leitura menos atenta do discurso das crianças poderá associar a regulamentação interna do funcionamento das casas abrigo a representações de algo constrangedor da liberdade individual e controlador das opções, e como tal, prejudicial. No entanto, percebe-se, em alguns casos de forma explícita e noutros implícita, que as regras cumprem a sua finalidade disciplinadora da ação 
das crianças. Não deixa de ser revelador o fato de alguns menores, apesar de terem demonstrado alguma resistência às normas de funcionamento, avaliarem as mesmas como justas e necessárias e quando lhes é dada a possibilidade de pensarem mudanças na instituição de acolhimento a maioria não faz referência a alteração das normas, o que nos leva a questionar se o setting em causa não responde de fato às necessidades das mesmas. Esta aparente resistência às regras denota a não aprendizagem e interiorização dos limites impostos por figuras de autoridade, indiciando padrões irregulares e disfuncionais do funcionamento familiar e possivelmente práticas educativas permissivas, baseadas na ausência de limites e baixa monitorização.

Finalmente, as casas abrigo são identificadas como um contexto promotor do sentimento de segurança física e psicológica (segurança). O restabelecimento do sentimento de segurança, em contraste com a ameaça percebida no período de violência, é determinante na normalização/minimização da experiência emocional, cognitiva e comportamental das crianças e na perda do protagonismo do tema violência. A ameaça ao sentimento de segurança surge associada a uma eventual proximidade com a figura paterna (crença na reincidência da violência). Apesar destes progressos, a recordação do passado torna visíveis algumas sequelas psicológicas, que se consubstanciam em reações de algum afeto negativo e de evitação. Este fato alerta-nos para a necessidade de se desenvolverem esforços terapêuticos com a população infantil em acolhimento, uma vez que a percepção do passado recente constitui um bom indicador quanto à superação, ou não, da situação traumática e quanto à integração dos acontecimentos na história de vida de cada criança. A transição para um contexto seguro parece atenuar as marcas psicológicas, mas estas não desaparecem por si só.

O estudo permitiu tirar importantes ilações sobre as casas abrigo como resposta social no âmbito da violência doméstica, as quais deverão dar lugar a uma proposta de reflexão das práticas e procedimentos adotados. Ficou a sensação de que existe ainda muito trabalho a desenvolver, com especial destaque para a necessidade de se promover maior e melhor divulgação/ informação sobre as respostas sociais existentes de combate à violência doméstica (e.g. como é e como funciona uma casa abrigo), de forma a dar lugar a representações mais próximas do real.

O grande desafio que se perspectiva com este, e outros trabalhos que se façam na área, coloca-se ao nível da incorporação dos resultados dos estudos nas práticas das organizações e dos profissionais que diariamente trabalham com esta população. Neste sentido, um esforço acrescido terá que ser feito na abertura de canais de comunicação entre produtores e utilizadores de conhecimento. Paralelamente, e baseando a seguinte argumentação na sensibilidade adquirida ao longo de três anos de profissional numa casa abrigo, somos da opinião que deverão ser realizados esforços no sentido de colmatar algumas lacunas que poderão estar na base de práticas menos adequadas, nomeadamente, a escassez de formação sobre a temática, o isolamento profissional dos técnicos que impossibilita a partilha de experiências, esclarecimento de dúvidas e aperfeiçoamento de intervenções bem como a quase inexistente avaliação técnica no interior das equipes e externa.
Consideramos ainda pertinente tecer algumas considerações em torno do potencial que estes espaços (casas abrigo) encerram ao nível da intervenção (individual e/ou grupal) e possível prevenção. Ficou claro que as dificuldades de ajustamento das crianças não desaparecem por si só, ainda que sejam minimizadas pelo fim da exposição à violência e transição para um ambiente mais organizado e estável, exigindo por isso um acompanhamento especializado e ajustado às necessidades das mesmas. A transição e ingresso nas instituições de acolhimento encerram em si simultaneamente risco e oportunidade, pelo que deve haver da parte das equipas técnicas um trabalho terapêutico sério e especialmente intensivo e focalizado na fase inicial do acolhimento, no sentido de minimizar as perdas que a institucionalização acarreta e maximizar as suas potencialidades. Em nosso entender, o essencial das preocupações interventivas nestes settings, não se devem centrar unicamente ao nível remediativo mas também (e principalmente) ao nível preventivo, uma vez que as crianças serão os futuros homens e mulheres.

Não se pense, no entanto, que esta investigação se trata de um trabalho acabado, mas sim um meio de identificar e explorar temas que servem de reflexão a esta área de intervenção e a estudos posteriores. Precisamos expandir os nossos paradigmas para explicar como a violência perturba o desenvolvimento individual da criança e invade esferas mais abrangentes da sua vida. O desafio que se coloca nas investigações futuras implica movermo-nos da simples análise causa-efeito para desenhos empíricos mais complexos. A este nível, parece-nos que seria interessante levar a cabo estudos que analisem o ajustamento das crianças antes e após o acolhimento em casa abrigo, de forma a percebermos a evolução das dificuldades, que de resto constituiu uma limitação no nosso estudo. O desenvolvimento de estudos longitudinais com esta população, no sentido de perceber os sentidos que se vão desenvolvendo com o tempo, parece-nos outro caminho que se perspectiva como promissor. Estudos a partir de múltiplos informantes também se revelam como tendo potencial informativo. Investigação qualitativa nos efeitos da cessação do contacto pai-criança parece-nos igualmente necessária.

\section{Referências}

Baptista, I., Silva, M. J., \& Nunes, J. (2004). National Report Portugal. Cesis: Portugal.

Ericksen, J. R., \& Henderson, A. D. (1992). Witnessing family violence: the childrens experience. Journal of Abnormal Nursing, 17, 1200-1209.

Fantuzzo, J. W., Mohr, W. K., \& Noone, M. L. (2000). Making invisible victims of violence against woman visible through University/Community partnerships. Em R. A. Geffner, P. G. Jaffe \& M. Sudermann (Eds.), Children exposed to domestic violence. Current issues in research, intervention, prevention and policy development (pp. 9-23). New York: The Haworth Maltreatment \& Trauma Press.

Coutinho, M. J. (2008). Histórias de Vida Tocadas pela Violência: Impacto e Representações das Crianças Vitimas de Violência Interparental. Dissertação de Mestrado, Universidade de Trásos-Montes e Alto Douro (UTAD), Vila Real. 
Peled, E. (1998). The experience of living with violence for preadolescent children of battered women. Youth \& Society, 29, 395-430.

Rodrigues, A. C. (2006). De que é feito o amor entre os pais que se batem? Significados de amor, conjugalidade, papéis de género e violência em adolescentes expostos a violência doméstica. Dissertação de Mestrado, Universidade do Porto, Porto.

Sani, A. I. (1999). Entrevista de avaliação - intervenção com crianças vitimizadas [Resumo]. Actas do Congresso Avaliação Psicológica: formas e contextos, 6, 363-374.

Sani, A. I. (2002). As crianças e a violência: Narrativas de crianças vitimas e testemunhas de crimes. Coimbra: Quarteto Editora.
Sani, A. I. (2003). As crenças, o discurso e a acção: as construções de crianças expostas à violência interparental. Tese de Doutorado, Universidade do Minho, Braga.

Sani, A. I. (2004). O discurso de crianças expostas à violência interparental: Estudo qualitativo. Psychologica, 36, 109-130

Recebido em 30.07.09 Primeira decisão editorial em 10.02.10 Versão final em 03.03.10 Aceito em 19.03.10 